\title{
Low temperature tolerance and osmotic regulation in the amphipod Gammarus oceanicus from Spitsbergen waters
}

\author{
ARNE VOLLAN AARSET AND KARL ERIK ZACHARIASSEN
}

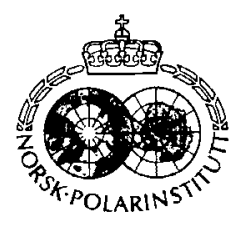

Aarset, A. V. \& Zachariassen, K. E. 1988: Low temperature tolerance and osmotic regulation in the amphipod Gammarus oceanicus from Spitsbergen waters. Polar Research 6, 35-41.

The amphipod Gammarus oceanicus can survive being frozen into solid sea ice at a temperature of -6 to $-7^{\circ} \mathrm{C}$. The animals appear to be supercooled at this temperature. No thermal hysteresis agents were present in the haemolymph, and the prevention of internal freezing in the animals thus requires a body surface with a low permeability to water and ice. Gammarus oceanicus is a euryhaline species. Below $700 \mathrm{mOsm}$ seawater, it displays a very efficient osmoregulation, whereas it is an osmoconformer at seawater osmolalities above this value. At $+5^{\circ} \mathrm{C}$ the amphipods die whenever their body fluid osmolality exceeds about $1000 \mathrm{mOsm}$. When the animals are trapped in freezing seawater, the osmolality of the brine may exceed this value considerably. The tolerance of the animals to hyperosmotic stress thus seems to be higher at subzero temperatures than at $+5^{\circ} \mathrm{C}$.

Arne Vollan Aarset and Karl Erik Zachariassen, Department of Zoology, University of Trondheim, 7055 Dragvoll, Norway; October 1987 (revised March 1988).

The amphipod Gammarus oceanicus is abundant in shallow subtidal waters in the fiords of Spitsbergen. In the cold season a thick layer of landfast ice covers the littoral and the upper parts of the sub-littoral zone. Under these circumstances the amphipods, being highly mobile, can escape from the ice cover by migration to deeper waters. On the other hand, many epibenthic amphipods have been observed in close association with sea ice (Newbury 1983), and they might therefore be trapped within the ice as it freezes to the bottom in shallow water areas.

Amphipods trapped within the ice are exposed to temperatures well below those normally experienced by marine animals. Green \& Steele (1975) have reported from the Canadian Arctic that the amphipod Gammaracanthus loricatus was associated with ice stalactites under landfast ice, and might sometimes be frozen within them. When water freezes out, the salts are excluded in a brine (Weeks 1968; Cox \& Weeks 1974) which may impose a hyperosmotic stress on the amphipods in addition to the low temperature exposure.

During spring and summer, the fiords of Spitsbergen receive a considerable amount of fresh water from melting ice, leaving the surface layer brackish. Consequently, the amphipod Gammarus oceanicus is likely to be exposed to salinities varying over a wide range. A similar situation has been reported from the Canadian Arctic, where the benthic amphipod, Onisimus affinis, may be exposed to low salinity melt water (Percy 1975). The osmotic stress that these variations exert upon the amphipods must be dealt with by means of efficient osmoregulatory mechanisms. The purpose of the present study has been to investigate the ability of Gammarus oceanicus to tolerate osmotic stress and low temperature, and to obtain insight into the physiological mechanisms involved.

\section{Material and methods}

\section{Animals}

The present study was carried out in Ny-Ålesund, Spitsbergen, in late July/early August 1983 and in November 1984. Amphipods of the species Gammarus oceanicus were collected from the beach at low tide and transported to the laboratory in a thermos bottle filled with seawater. They 
were kept in this seawater $(300-350 \mathrm{mOsm})$ at a temperature of $+5^{\circ} \mathrm{C}$, inside a refrigerator, and acclimatized to laboratory conditions for at least 24 hours before they were used in experiments. During this period, individuals that were in a bad condition could be removed. The amphipods were not fed, and only intermolt animals were used in the experiment (Charniaux-Legrand 1952). The size of the amphipods ranged from 15 to $25 \mathrm{~mm}$, measured from rostrum to base of telson.

\section{Freezing experiments}

The freezing experiments were arranged in a Hetofrig cooling bath, where the temperature could be regulated within $\pm 0.05^{\circ} \mathrm{C}$. Experiments to study the effect of freezing amphipods into sea ice were carried out by using the arrangement shown in Fig. 1. A $20 \mathrm{ml}$ plastic syringe, containing about $10 \mathrm{ml}$ of seawater, was submerged into the cooling bath. A piece of cotton was put into the water and the amphipod placed on top of the piece. The seawater was then cooled to a temperature just below its melting point $(-1$ to

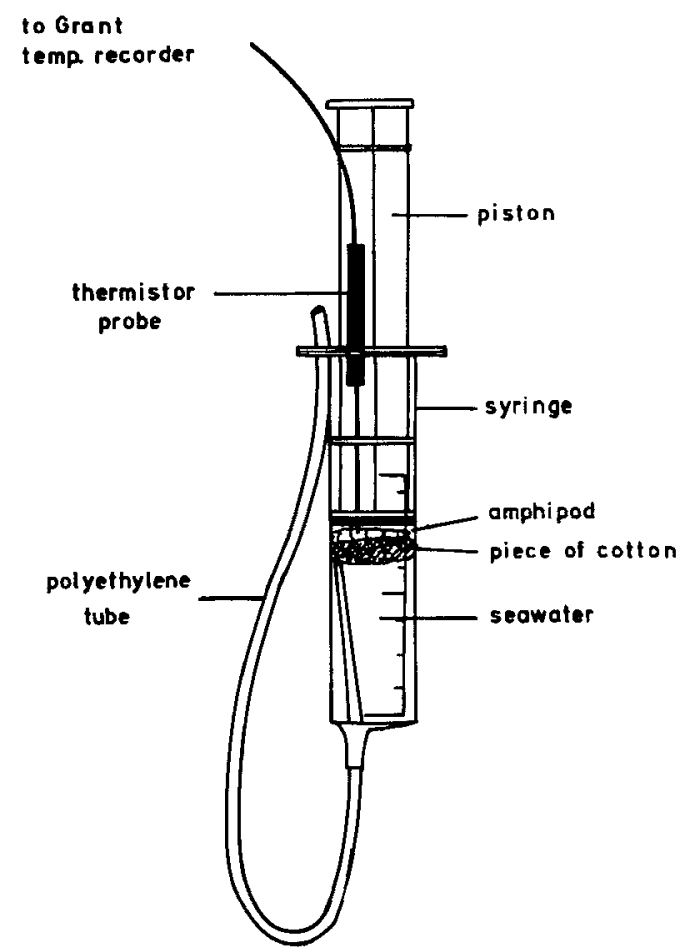

Fig. 1. Instrument used for studying freezing of $G$. oceanicus in freezing seawater (see text). $-2^{\circ} \mathrm{C}$ ), whereafter freezing was initiated by seeding with ice crystals from the top of the syringe. The piston of the syringe was then pushed down just far enough to immerse the amphipod in the water near the surface. A thermistor probe was then brought into the water through a hole in the piston, and the temperature of the freezing water sample was registrated continuously on a Grant temperature recorder.

The piston could be moved freely up and down in the syringe, as air pressure differences were eliminated by means of a polyethylene tube inserted into the syringe through the outlet (Fig. 1). By seeding freezing of the seawater at a high subzero temperature, the seawater could be frozen and concentrated while the animal was still unfrozen, allowing the amphipod to conform its internal osmolality to that of the gradually more concentrated external medium, thus giving the animal an opportunity to avoid freezing.

In five separate runs the cooling bath temperature was lowered to temperatures from $-2^{\circ} \mathrm{C}$ to $-8^{\circ} \mathrm{C}$, and the amphipods were exposed for about 12 hours to the lowest temperature. The syringes were then taken out of the water bath, and the seawater samples allowed to thaw slowly in air $\left(20^{\circ} \mathrm{C}\right)$ in order to study the survival of the amphipods. Individuals that did not move when touched were recorded as dead.

In other experiments the frozen seawater clot was pushed out of the syringe at each low temperature exposure $\left(-4^{\circ} \mathrm{C}\right.$ to $\left.-6^{\circ} \mathrm{C}\right)$, and the animals were cut out of the still frozen clots. A haemolymph sample was taken immediately after thawing in order to get a measure of the body fluid osmolality of the animals trapped inside the 'pocket' of highly concentrated seawater.

\section{Supercooling the THF}

Supercooling points of intact amphipods, blotted dry with filter papers, were determined with the animals kept inside a plastic tube in contact with a thermistor probe $(\mathrm{d}=0.6 \mathrm{~mm})$ which was connected to a Grant temperature recorder. A low cooling rate (about $0.1^{\circ} \mathrm{C}$ per min.) was established by mounting two isolating air filled plastic tubes around the inner tube containing the animal before immersion into the ethanol/water cooling bath, preset to $-20^{\circ} \mathrm{C}$. The supercooling point was registered by an abrupt increase in the temperature due to the release of the heat of fusion.

The presence of thermal hysteresis factors 
(THFs) in the haemolymph of the amphipods was investigated by measuring the melting and freezing points of the haemolymph samples on a Clifton osmometer (DeVries 1982; Zachariassen \& Husby 1982).

\section{Osmotic experiments}

The osmotic regulation of the amphipods was studied by transferring the animals to various solutions of seawater/sea-salt at a constant temperature of $+5^{\circ} \mathrm{C}$. Dilute solutions were made by diluting seawater with distilled water, whereas solutions more concentrated than seawater were made by adding sea salts to a seawater sample previously reduced in water content by evaporation at $+95^{\circ} \mathrm{C}$, yielding a final stock solution of about $4100 \mathrm{mOsm}$. The stock solution was subsequently diluted with seawater. The animals were allowed to acclimatize in the respective solutions for about 12 hours, then their survival and haemolymph osmolality were observed.

In another series of experiments, the survival of the amphipods and the change in their internal osmolality were determined as a function of time after transferring the animals from the acclimation seawater $(300 \mathrm{mOsm})$ to various solutions, the osmolalities of which ranged from 900 to $4100 \mathrm{mOsm}$. The behaviour of the amphipods was observed, and at different intervals animals were removed for haemolymph sampling. The experiments were interrupted when the osmolality had stabilized at a constant value, or when the animals were too seriously affected (dead or dying). Only animals which were swimming in an apparently normal manner and animals which displayed normal, coordinated movements were defined as 'surviving'. Animals which displayed uncoordinated movements or which did not move at all were defined as 'dead'.

\section{Sampling}

Samples $(2-15 \mu \mathrm{l})$ of haemolymph were obtained by inserting a pointed, paraffin-filled glass capillary dorsally through the intersegmental membrane. The capillary was sealed in one end by melting in a gas flame and centrifuged on a Compur 1100 micro centrifuge, leaving the haemolymph sample isolated under a layer of paraffin-oil (Zachariassen et al. 1982). The capillaries were stored in a deep freezer $\left(-25^{\circ} \mathrm{C}\right)$.

\section{Analytical methods}

The osmolality of the seawater and the haemolymph were determined by using a Clifton nanolitre osmometer, where the melting point of 30$50 \mathrm{nl}$ samples was measured as the temperature at which the last tiny ice crystal disappeared when previously frozen samples were slowly heated.

\section{Results}

\section{Freezing experiments}

The effect of freezing amphipods into solid sea ice at desired temperatures is shown in Fig. 2. The ice crystal growth proceeded from the surface and downward in each syringe, and the ice did not stop growing until both the ice and the unfrozen seawater fraction reached the preset ambient cooling bath temperature. The seawater in contact with the sea ice is thus kept at a temperature corresponding to the melting point of the brine (Maykut 1985).

The results indicate that none of the animals died when they were exposed to temperatures from $-2^{\circ} \mathrm{C}$ to $-5.2^{\circ} \mathrm{C}$ (Fig. 2). However, after an exposure to $-8^{\circ} \mathrm{C}$ all the animals died. In the temperature range from $-5.2^{\circ} \mathrm{C}$ to $-6.5^{\circ} \mathrm{C}$ the injury frequency increased rapidly, with about $75 \%$ survival at $-6.5^{\circ} \mathrm{C}$. Freezing did not seem to affect significantly the osmolality of the body fluids of the amphipods. Following freezing to $-4,-5$ and $-6.5^{\circ} \mathrm{C}$ for 12 hours, the body fluid

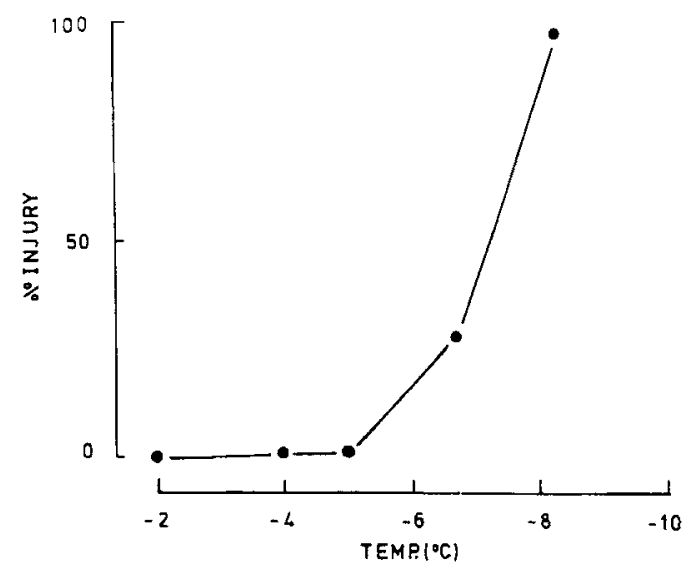

Fig. 2. Injury frequency of $G$. oceanicus following cooling in sea water to various temperatures. The total number of animals is 15,3 for each point. 
Table 1. Haemolymph osmolality of Gammarus oceanicus exposed to low temperatures for 12 hours. Mean \pm SD (n).

\begin{tabular}{lc}
\hline Exposure temp. ${ }^{\circ} \mathrm{C}$ & Osmolality mmole $/ \mathrm{kg} \mathrm{H}_{2} \mathrm{O}$ (mOsm) \\
\hline+5 & $586 \pm 33(6)$ \\
-4 & $657 \pm 76(3)$ \\
-5 & $677 \pm 46(2)$ \\
-6.5 & $785 \pm 14(3)$ \\
\hline
\end{tabular}

of the crustaceans was only slightly concentrated as compared to the body fluids of animals living in normal seawater (Table 1).

\section{Supercooling and THF}

The mean supercooling point of 4 crustaceans blotted dry with filter paper was $-6.5^{\circ} \mathrm{C}$ (Table 2). All the animals died following freezing. There was no significant difference between the melting and freezing point of the haemolymph (Student$t$ test), indicating that no thermal hysteresis factor was present in the body fluids of the animals.

\section{Osmotic experiments}

The haemolymph osmolality steady state levels were determined after an acclimatization period of 12 hours to different experimental media (osmolalities from 0 to about $1000 \mathrm{mOsm}$ ) at $5^{\circ} \mathrm{C}$ (Fig. 3). The results reveal that the animals are osmoconformers in the media ranging from about $700 \mathrm{mOsm}$ to about $900 \mathrm{mOsm}$. Below $700 \mathrm{mOsm}$ the haemolymph osmolality showed only a moderate drop with decreasing osmolality in the external medium, revealing that over this osmolality range, the animals were efficient osmoregulators. The animals were also able to maintain their internal osmolality at about the normal level when they were kept in fresh water from the tap.

Fig. 4 shows the body fluid osmolality and state of animals which were kept in seawater with different osmolalities, plotted as a function of the

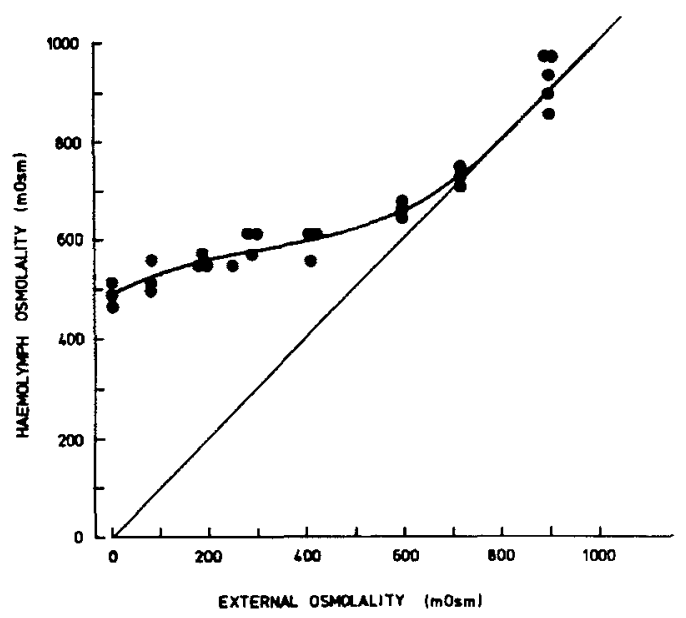

Fig. 3. Haemolymph osmolality of $G$. oceanicus as a function of the osmolality of the external medium. Each point represents one animal. The solid line represents unity. The temperature was $+5^{\circ} \mathrm{C}$.

exposure time. In animals acclimatized to 890 mOsm solution, the haemolymph osmolality reached a steady state after about 3 hours, the body fluid being isosmotic or slightly hyperosmotic to the external medium. All animals displayed normal activity at this concentration.

In animals transferred to $1930 \mathrm{mOsm}$ seawater, the haemolymph osmolality was still increasing after 6 hours. After 12 hours the haemolymph osmolality had reached the osmolality of the external medium (not shown in the figure). Injuries started to occur after $90 \mathrm{~min}$, when the body fluid concentration passed $1000 \mathrm{mOsm}$. Exposure to higher concentrations in the external medium caused a more rapid increase in the body fluid concentration and a correspondingly more rapid development of injuries. Regardless of the concentration of the external medium, injuries seemed to develop whenever the haemolymph concentration exceeded 1000 mOsm.

Table 2. Thermal data $\left({ }^{\circ} \mathrm{C}\right)$ of the arctic amphipod Gammarus oceanicus. $\Delta_{\mathrm{scp}}$ : supercooling points, $\Delta_{\mathrm{fp}}$ : freezing points, $\Delta_{\mathrm{m}}$ : melting points.

\begin{tabular}{lcccc}
\hline Number of samples & $\Delta_{\text {scp }}$ & $\Delta_{\mathrm{fp}}$ & $\Delta_{\mathrm{m}}$ & $\Delta_{\mathrm{tp}}-\Delta_{\mathrm{m}}$ \\
\hline $4_{\mathrm{a}}$ & $-6.3 \pm 0.3$ & $-1.13 \pm 0.04$ & $-1.12 \pm 0.03$ & $-0.01 \pm 0.05$ \\
$3_{\mathrm{b}}$ & & $-1.79 \pm 0.05$ & $-1.76 \pm 0.03$ & $-0.03 \pm 0.06$ \\
\hline
\end{tabular}

a: August, b: November 
Fig. 4. Hacmolymph osmolality of $G$. oceanicus acclimatized to different salinities as a function of time. The temperature was $+5^{\circ} \mathrm{C}$. $\diamond: 410 \mathrm{mOsm}$. 0 : 890 mOsm. $\Delta$ : $1930 \mathrm{mOsm}$.

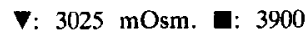
mOsm. Open symbols indicate animals in good condition, whereas closed symbols represent dead or seriously injured animals. The dashed line indicates the highest tolerable body fluid osmolality.

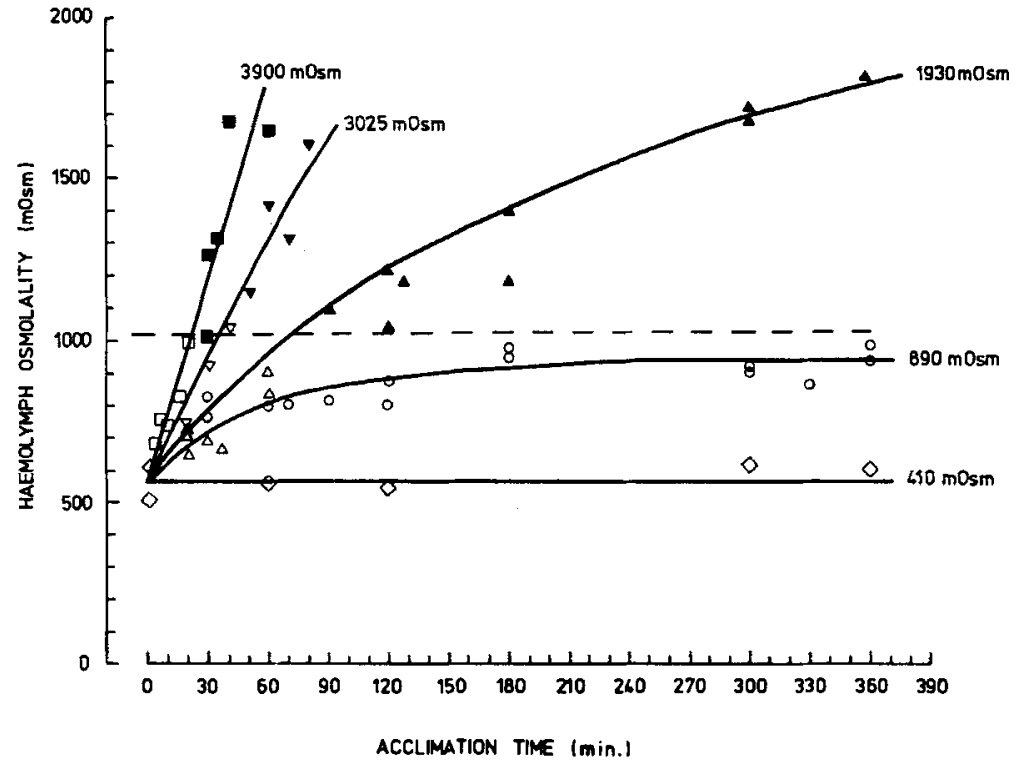

\section{Discussion}

The present results reveal that when $G$. oceanicus amphipods are cooled in air, they will freeze and die at a temperature of about $-6.5^{\circ} \mathrm{C}$. These relatively high supercooling points indicate that some kind of nucleating agents are present in the body fluids of the animals (Zachariassen 1980). Animals cooled in freezing seawater are also likely to freeze at about $-6.5^{\circ} \mathrm{C}$, unless the increasing external osmolality during freezing of the medium causes an increase in the body fluid osmolality of the animals. An increased body fluid osmolality would probably cause a colligative depression of the supercooling points (Zachariassen \& Hammel 1976). However, the present results indicate that the body fluid osmolality increases moderately as the external medium freezes (Table 1). Thus, the supercooling points observed in animals cooled in air are likely to be representative also of the temperatures at which the animals will freeze spontaneously when cooled in freezing seawater.

Since the body fluid osmolality of the animals does not increase significantly when the animals are cooled in a frozen medium, they appear to be supercooled under such circumstances. The prevention of internal freezing of the animals under these conditions requires a body surface with a low permeability to water and ice. The survival of the animals could also depend on the presence in their body fluids of so-called thermal hysteresis agents, which are proteinaceous compounds acting to stabilize animals in a supercooled state (DeVries 1982; Duman 1979; Zachariassen \& Husby 1982). However, tests for thermal hysteresis agents carried out in August 1983 and in November 1984 were negative (Table 2), indicating that THFs are not present in these animals neither in summer nor wintertime. On the other hand, freezing may occur even during springtime, as meltwater penetrates the ice from above (Martin \& Kauffman 1973).

The present results reveal that animals cooled in freezing seawater were injured even at temperatures above the supercooling points of animals cooled in air. This indicates that injury mechanisms other than spontaneous internal freezing are involved. One possible mechanism responsible for injuries of this type could be seeding of external ice through the body surface. The cold tolerance of Gammarus oceanicus, by freezing into solid ice, thus seems to be different from the amphipod Gammarus duebeni living in subArctic intertidal pools (Davenport 1979). For example, when the pools freeze at low tide the amphipods ( $G$. duebeni) aggregate at the bottom of the pools, at a distance away from the growing 
sea ice, conforming to the brine during the freezeup period.

The present results show that $G$. oceanicus is a euryhaline species being an osmoconformer at seawater osmolalities above about $700 \mathrm{mOsm}$, whereas in seawater osmolalities below this value they display a very efficient osmoregulation. These results agree well with the results obtained from the same species by Werntz (1963).

However, G. oceanicus amphipods seem to die whenever their body fluid osmolality exceeds about 1000 mOsm (Fig. 4). Since the amphipods at high medium osmolalities are isosmotic with the external medium (Fig. 3), $1000 \mathrm{mOsm}$ is also likely to represent the highest concentration of seawater tolerated by the animals over an extended period of time, except when they are trapped in the brine of freezing seawater. Brodie \& Halcrow (1978) have also demonstrated a poor ability of $G$. oceanicus, from Arctic Canada, to regulate under hypersaline conditions. The animals were found to be able to survive such unfavourable conditions for a short time, i.e. until the incoming tide restored the normal salinity.

The data in Fig. 4 show that at $+5^{\circ} \mathrm{C}$ the animals will attain an internal osmolality of $1000 \mathrm{mOsm}$ and die after about $90 \mathrm{~min}$ at a medium osmolality of $1930 \mathrm{mOsm}$ and after only $30 \mathrm{~min}$ in a medium of $3025 \mathrm{mOsm}$. However, when the animals are trapped in freezing seawater, the osmolality of the brine may exceed these values considerably. Nevertheless, as shown in Fig. 2, only a small fraction of the animals was injured when they were frozen for two hours at -4 and $-5.2^{\circ} \mathrm{C}$. These temperatures correspond to brine concentrations of about 2000 and $3000 \mathrm{mOsm}$, respectively. These observations may suggest that the tolerance of the animals to high external salinities is higher at subzero temperatures than at $+5^{\circ} \mathrm{C}$. This is consistent with the observation that following freezing to $-6.5^{\circ} \mathrm{C}$ for 12 hours there was only a slight increase in the body fluid osmolality of the animals (Table 1 ).

An improved survival in high salinities at low temperature is known for several invertebrate species (Panikkar 1940; Kinne 1956; Verwey 1957; Williams 1960; Dorgelo 1977; Burton 1986). The present observations of low temperatureinduced tolerance of $G$. oceanicus to hypersaline seawater may indicate that the permeability to water through the body surface of the animals is considerably lower at subzero temperatures than at $+5^{\circ} \mathrm{C}$. This could be a mechanism acting to increase the survival of the animals in freezing sea ice. Injury mechanisms other than those associated with high body fluid concentrations could thus be involved, providing further evidence to the conclusion that the animals are injured by seeding of external ice.

Acknowledgements. - The present study has been financed by the Norwegian Polar Research Institute, Oslo, and the Norwegian Research Council for Science and Humanities (PRO MARE).

\section{References}

Brodie, D. A. \& Halcrow, K. 1978: Haemolymph regulation to hyposaline and hypersaline conditions in Gammarus oceanicus (Crustacea: Amphipoda). Experientia 34, 12971298.

Burton, R. F. 1986: Ionic regulation in Crustacea: The influence of temperature on apparent set points. Comp. Biochem. Physiol. 84A, 135-139.

Charniaux-Legrand, H. 1952: Le cycle d'intermue des Amphipodes, ses particularities chez les formes terrestres (Talritidae). Archs. Zool. exp. gen. 88, 1297-1298.

Cox, G. F. N. \& Weeks, W. F. 1974: Salinity variations in sea ice. J. Glaciol. 67, 109-120.

Davenport, J. 1979: Cold resistance in Gammarus duebeni Liljeborg. Astarte 12, 21-26.

DeVries, A. L. 1982: Antifreeze agents in coldwater fishes. Comp. Biochem. Physiol. 73A, 627-640.

Dorgelo, J. 1977: Comparative ecophysiology of gammarids (Crustacea: Amphipoda) from marine, brackish and freshwater habitats exposed to the influence of salinity-temperature combinations. IV. Blood sodium regulation. Neth. J. Sea Res. 11, 184-199.

Duman, J. G. 1979: Thermal hysteresis-factors in overwintering insects. J. Insect Physiol. 25, 805-810.

Green, J. M. \& Steele, D. H. 1975: Observation of marine life beneath sea ice, Resolute Bay, NWT. Proc. Circum. Conf. Northern Ecol. 2, 77.

Kinne, O. 1956: Über Temperatur und Saltzgehalt und ihre physiologisch- biologische Bedeutnung. Biol. Zbl. 75, 314327.

Martin, S. \& Kauffman, P. 1974: The evolution of under-ice melt ponds, or double diffusion at the freezing point. $J$. Fluid Mech. 64, 507-527.

Maykut, G. A. 1985: The ice environment. Pp. 21-82 in Horner, R. A. (ed.): Sea ice biota. CRC Press, Florida. 215 pp.

Newbury, T. K. 1983: Under landfast ice. Arctic 36, 328-340.

Panikkar, N. K. 1940: Influence of temperature on osmotic behaviour of some Crustacea and its bearing on problems of animal distribution. Nature, Lond. 146, 366-367.

Percy, J. A. 1975: Ecological Physiology of Arctic marine invertebrates. Temperature and salinity relationships of the amphipod Onisimus affinis H. J. Hansen. J. Exp. Biol. 32, $618-630$.

Verwey, J. 1957: A plea for the study of temperature influence on osmotic regulation. Année biol. 33, 129-149.

Weeks, W. F. 1968: Understanding the variations of the physical properties of sea ice. Symp. Antarc. Ocean, Chile, 173-190. 
Werntz, H. O. 1963: Osmotic regulation in marine and freshwater Gammarids (Amphipoda). Biol. Bull. 124, 225-239.

Williams, A. B. 1960: The influence of temperature on osmotic regulation in two species of estuarine shrimps (Penaeus). Biol. Bull. mar. biol. Lab., Woods Hole 119, 560-571.

Zachariassen, K. E. 1980: The role of polyols and nucleating agents in cold hardy beetles. J. comp. Physiol. 140, 227-234.

Zachariassen, K. E. \& Hammel, H. T. 1976: Nucleating agents in the haemolymph of insects, tolerant to freezing. Nature $262,285-287$.

Zachariassen, K. E., Baust, J. G. \& Lee, R. E. 1982: A method for quantitative determination of ice nucleating agents in insect haemolymph. Cryobiology 19, 180-184.

Zachariassen, K. E. \& Husby, J. A. 1982: Antifreeze effect of thermal hysteresis agents protects highly supercooled insects. Nature 298, 865-867. 
